\title{
A Novel Method for Determination of Kinetic Friction Coefficient using Inclined Plane
}

\author{
Djordje VUKELIC*, Petar TODOROVIC, Katica SIMUNOVIC, Jasmina MILJOJKOVIC, Goran SIMUNOVIC, Igor BUDAK, Branko TADIC
}

\begin{abstract}
Presented in this paper is the theoretical background for a novel method for determination of kinetic friction coefficient. The method is based on the equation of movement of a rigid body along an inclined plane and has not been previously discussed in literature. According to the theoretical results presented in this paper, mean kinetic friction coefficient can be determined based on the time it takes a rigid body to travel a distance along an inclined plane. Experimental results show that the mean kinetic friction coefficient increases with increasing mean sliding velocity, i.e. with decreasing sliding time. Increasing sliding velocity increases deviation of friction coefficients. This method also allows the determination of energy consumed due to friction along the travelled distance. Increasing mean kinetic friction coefficient and mean sliding velocity increases energy consumed due to friction. Practical calculation requires application of the distance law, which, in turn, requires accurate measurement of the sliding time and distance.
\end{abstract}

Keywords: friction coefficient; kinetic friction; sliding friction

\section{INTRODUCTION}

Friction is a complex phenomenon which takes place at surface contacts. As such, friction has been the subject of interest for more than 400 years [1]. It exists as either the static or the kinetic friction [2], which is the result of a relative motion between two bodies. Static friction force increases with tangential displacement, until it reaches value which allows relative motion between two bodies in contact. Even though in a macroscopic sense two bodies are static, there exists a micro-displacement between them. This displacement termed as initial displacement occurs in the contact zone and precedes the relative motion. Microdisplacement can reach relatively high values when one of the contact surfaces features small tangential stiffness compared to the other contact surface. A typical example is the contact between rubber and metal.

Friction coefficient is a characteristic of every tribological system. Knowing friction coefficients is of utmost importance during development, maintenance and optimization of contact pairs, which are to be implemented in industrial systems. However, literature sources cannot be always relied upon when it comes to friction coefficients. The problems are primarily related to unknown circumstances under which the literary data have been obtained, i.e., measured, knowing that the reported friction coefficient values differ from one laboratory to another, depending on the measuring equipment, measuring methodology, and other numerous factors which affect final results. Blau [3] reported on the most common, standard-defined measurement methods used for obtaining either static or kinematic friction coefficients, as well as the ways of their application. A number of factors influence friction coefficient values, primarily: materials, load, surface roughness, sliding velocity, sliding mode, coating, lubricant, temperature, humidity, etc. [3-7].

Numerous studies have investigated the influence of the previously listed factors on the friction phenomenon, mostly focusing on the measurement and modelling methods.

Kogut and Etsion [8] presented a model that predicts the static friction for elastic-plastic contact of rough surfaces. The model showed that the main dimensionless parameters affecting the static friction coefficient are the plasticity index and adhesion parameter. Higher plasticity index decreased the friction coefficient. Cohen et al. [9] developed a model for elastic-plastic contacting rough surfaces under combined normal and tangential loading with full stick contact condition. Empirical equations for the static friction coefficient were derived as functions of the dimensionless normal load, material properties, and surface roughness. Ibrahim Dickey et al. [10] measured the static friction coefficient between tin surfaces under various loads. The static friction coefficient showed a repeated trend of decreasing as the load was increasing. Fujii [11] developed a method for measuring the friction coefficient between sliding solids. In the proposed method, both frictional and normal forces were measured as inertial forces acting on masses. Hwang and Zum Gahra [12] studied the frictional behaviour of both the static and sliding friction under unlubricated or oil lubricated conditions. Static friction coefficient and transition from static to kinetic friction were determined. The results showed a significant effect of surface finish on both the static and kinetic friction coefficients as well as on the transition behaviour. Transition behaviour was strongly dependent on the materials mated. Al-Bender and De Moerlooze [13] investigated the relation between the normal load and the friction force in the pre-sliding regime up to gross sliding. A Maxwell-Slip model strategy was supplied with model parameters, determined by an existing physics-based model. The friction coefficient was little affected by the elasticity, the hardness and the distribution of the asperity heights, but decreased with the increasing normal load, surface roughness and plasticity index. Benabdallah [14] analysed the impact of normal load, dwell time before slip, apparent area of contact and lubrication by water and paraffin oil on the static friction. Static friction coefficient decreases with the increase of normal load, spinning acceleration rate, and the increase of the apparent area of contact. Ando et al. [15] performed two kinds of friction coefficient measurements under low normal loads and in high vacuum. Friction coefficients of different metal pairs were determined by the difference in the interatomic distances within each material. The results showed that the friction coefficient increased when the interatomic distance of the metal approached $3.1 \AA$. Podgursky et al. [16] investigated the influence of 
geometrical parameters of the coated surface on the friction coefficient at the initial period of fretting contact. They found that the friction coefficient was inversely proportional to kurtosis, assuming positive skewness of the surface. Tayebi and Polycarpou [17] investigated the effect of kurtosis and skewness on the friction coefficient. Rather than increasing with increasing skewness, the static friction coefficient decreased with decreasing external force for high kurtosis values. Sedlacek et al. [18] investigated the influence of surface preparation on roughness parameters and correlation between roughness parameters and friction. Dry and lubricated pin-on-disc tests were carried out using different contact conditions. Friction coefficient was monitored as a function of time and wear of contact surface was determined after the test by means of topography analysis. Zhou et al. [19] studied friction coefficient within the lubricated sliding friction. The power spectrum, twoorder Renyi entropy were used to detect the nature of friction coefficient. The dynamic evolution of the friction coefficient was described by entropy. Chaikittiratana et al. [20] investigated the effect of temperature and contact pressure on static and kinetic friction coefficients. They found that both static and kinetic friction coefficients were unaffected by the variation of contact pressure. Temperature variation had a profound effect on static and kinetic friction coefficients as they increased approximately by two folds when the temperature was raised from $100{ }^{\circ} \mathrm{C}$ to $200{ }^{\circ} \mathrm{C}$. Cho et al. [21] explored effects of various velocities, load, and dwell time conditions on the static and kinetic friction of polymeric materials. Static and kinetic friction were dependent on the surface roughness which affected mechanical interaction of asperities and the real contact area. Cho and Bhushan [22] investigated friction of various polymer pairs used for labels and wipers in labelling machines. Friction tests were carried with various parameters such as load, velocity, and existence of varnish coating. Effect of load and velocity was elucidated from frictional heating and formation of tribo-film. Jeremic et al. [23] analysed friction at high temperatures and low contact pressures for contact pairs made of steel and bronze. The results of experimental investigation showed that at low contact pressure and temperature above $120{ }^{\circ} \mathrm{C}$ static friction coefficient dramatically increases. Kumar et al. [24] studied the sliding friction of titanium-modified austenitic stainless steel in high purity liquid sodium at high temperature. The results showed that the static friction coefficient was higher than the kinetic friction coefficient in all experiments. Yue and Wahab [25] analysed the effects of friction coefficient on wear volume and wear rate. Based on the energy model, finite element method was applied to cylinder/flat contact configuration exposed to constant normal load to study the effects of the friction coefficient on wear volume and wear rate. In gross sliding condition, friction coefficient had little effect on wear volume at the end of the steady statestage of fretting wear cycles. When considering partial slip or running-in stage of gross sliding conditions, models with variable friction coefficient achieved predictions closer to experimental results. Maegawa et al. [26] focused on the normal load dependence of the friction coefficient for the sliding friction of a rubber material with a rough surface. Based on the experimental results, an adhesion friction model was developed to explain the normal load dependence of the friction coefficient. Jankowiak et al. [27] presented a new methodology to define friction coefficient. The new methodology was developed numerically using finite element simulations of real experiments. The methodology included a correction factor for calculation of friction coefficient.

A large number of existing tribometer solutions worldwide has been ASTM and ISO standardized according to the conditions of establishing contacts. Following are some examples: TE 53 Multi-Purpose Friction and Wear Tester, TE 54 Mini Traction Machine, TE 55 Lubricity Test Machine, TE 56 Multi-Station Block on Ring Machine, TE 57 Pressurized Lubricity Tester. These tribometer designs are undergoing improvements today mostly with respect to software solutions and technical characteristics, such as increase of load, sliding and rolling velocities, working temperature, inclusion of vacuum chambers, etc. In a number of cases, standardized design solutions are used to derive tribometer designs with higher performance dedicated to investigations within significantly wider ranges of loads, sliding and rolling velocities, lubrication conditions, operating temperatures, presence of abrasives, etc. There are also a number of design solutions dedicated to tribological testing of gear trains, hard coatings, plastic masses, and other materials $[28,29]$.

Based on the analysis of literature sources, one can conclude that measurement methods and devices significantly affect reliability of measurement results. This is especially true if one considers the problems related to achieving identical conditions with respect to contact pairs micro geometry, i.e., surface roughness parameters.

Unlike previous investigations, this study proposes a novel theoretical model for determination of kinetic friction coefficient and presents experimental results. Based on the sliding distance and time, the proposed method allows determination of kinetic friction coefficient and related energy. In contrast to the previously discussed methods, the method proposed in this paper can be efficiently used in real industrial applications, i.e., for real contact pairs.

\section{THEORETICAL MODEL}

The theoretical model considers the determination of kinetic friction coefficient based on the time required for the body of mass $m$ to travel the distance $s$ along inclined plane which is illustrated in Fig. 1.

The equation of movement along an inclined plane (Fig. 1) is given as:

$m \cdot a=m \cdot \mathrm{g} \cdot \sin \alpha-F_{\mu}-F_{\mathrm{w}}$

where $a$ represents acceleration of body mass $m, \mathrm{~g}$ is acceleration of gravity, $F_{\mu}$ friction force, $F_{\mathrm{w}}$ air resistance, and $\alpha$ the angle of inclined plane. 


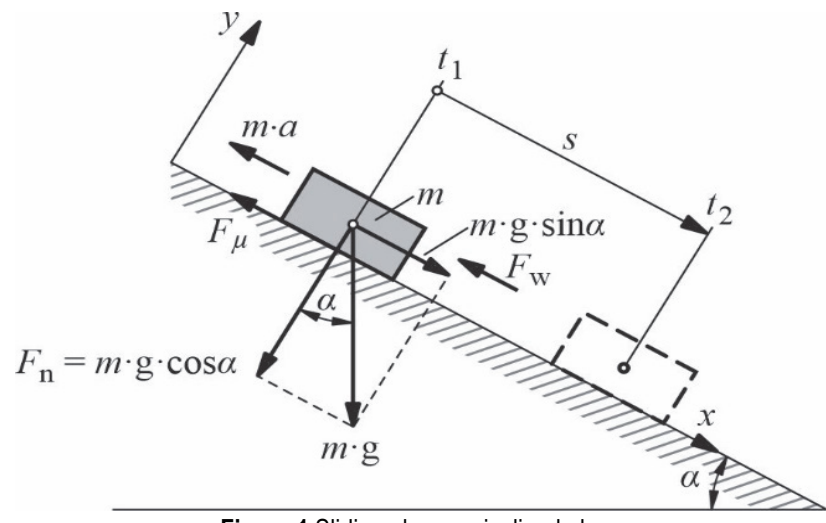

Figure 1 Sliding along an inclined plane

Friction force equals:

$F_{\mu}=\mu \cdot F_{\mathrm{n}}=\mu \cdot m \cdot \mathrm{g} \cdot \cos \alpha$

In the course of experimental investigations, conditions can be provided such that the air resistance can be disregarded, i.e. $F_{\mathrm{w}}=0$. Conditions under which that statement holds true are discussed in Section 4.

Eq. (1) can be written as:

$m \cdot \frac{\mathrm{d} v}{\mathrm{~d} t}=m \cdot \mathrm{g} \cdot \sin \alpha-\mu \cdot m \cdot \mathrm{g} \cdot \cos \alpha$

i.e.:

$\frac{\mathrm{d} v}{\mathrm{~d} t}=\mathrm{g} \cdot \sin \alpha-\mu \cdot \mathrm{g} \cdot \cos \alpha$

In an ideal case which represents the absence of friction $(\mu=0)$ and constant angle of inclined plane $(\alpha=$ const.), body velocity can be calculated based on Eq. (4):

$v=\mathrm{g} \cdot \sin \alpha \int \mathrm{d} t_{0}=\mathrm{g} \cdot t_{0} \cdot \sin \alpha+\mathrm{C}$

where $t_{0}$ represents the time required for the body to travel the distance $s$ without friction.

A case is considered when, at the initial moment, body velocity equals $v=0$, which means that $\mathrm{C}=0$. Now Eq. (5) can be written in the following form:

$v=\mathrm{g} \cdot t_{0} \cdot \sin \alpha$

Considering that in the general case $v=\mathrm{d} s / \mathrm{d} t$, integration of Eq. (6) over time yields equation which defines the change of travel distance in time:

$s=\frac{1}{2} \cdot \mathrm{g} \cdot t_{0}^{2} \cdot \sin \alpha$

Solving Eq. (7) for time $t_{0}$, gives the following equation:

$t_{0}=\sqrt{\frac{2 \cdot s}{\mathrm{~g} \cdot \sin \alpha}}$ allowing the calculation of time $t_{0}$ which takes body to travel the distance $s$ along an inclined plane without friction.

Under real conditions, a body moving down an inclined plane is acted upon by a frictional force $(\mu>0)$.

Friction coefficient is not constant through time, considering that the body velocity varies (increases) with time.

Using derivation:

$\frac{\mathrm{d} v}{\mathrm{~d} t}=\frac{\mathrm{d} v}{\mathrm{~d} s} \cdot \frac{\mathrm{d} s}{\mathrm{~d} t}=v \cdot \frac{\mathrm{d} v}{\mathrm{~d} s}$

Eq. (3) can be written as:

$m \cdot v \cdot \frac{\mathrm{d} v}{\mathrm{~d} s}=m \cdot \mathrm{g} \cdot \sin \alpha-\mu \cdot m \cdot \mathrm{g} \cdot \cos \alpha$

Integration of Eq. (10) yields:

$m \cdot \int v \cdot \mathrm{d} v=m \cdot \mathrm{g} \cdot \sin \alpha \cdot \int \mathrm{d} s-\int \mu \cdot m \cdot \mathrm{g} \cdot \cos \alpha \cdot \mathrm{d} s$

The value of integral $\left(\int \mu \cdot m \cdot \mathrm{g} \cdot \cos \alpha \cdot \mathrm{d} s\right)$ practically represents the energy consumed due to friction (Fig. 2), giving:

$A_{F_{\mu}}=\int \mu \cdot m \cdot \mathrm{g} \cdot \cos \alpha \cdot \mathrm{d} s=\int_{0}^{s} F_{\mu(s)} \cdot \mathrm{d} s_{\mu}=\bar{F}_{\mu} \cdot s=$

$=\bar{\mu} \cdot m \cdot \mathrm{g} \cdot \cos \alpha \cdot s$

where $\bar{\mu}$ represents mean kinetic friction coefficient.

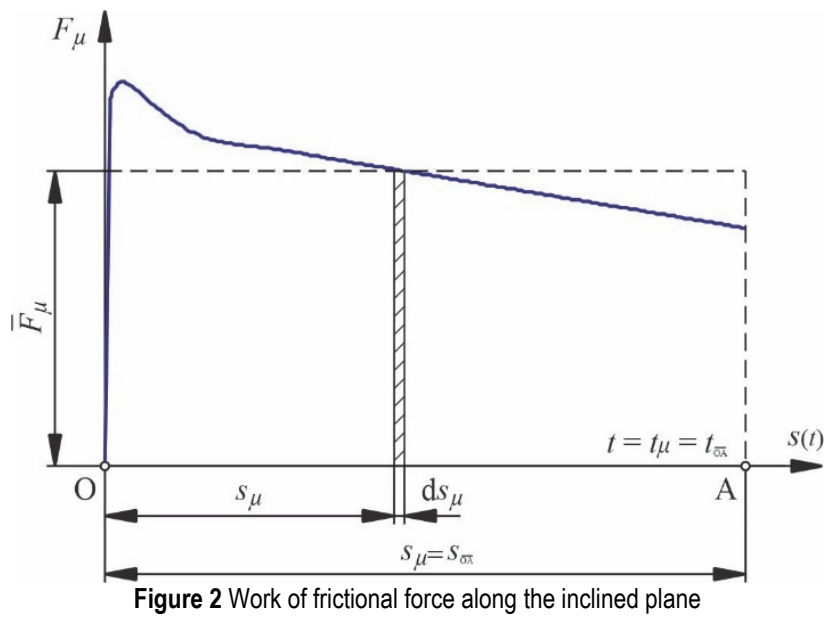

Now, Eq. (11) can be written in the following form:

$\frac{1}{2} \cdot m \cdot \bar{v}^{2}=m \cdot \mathrm{g} \cdot \sin \alpha \cdot s-m \cdot \mathrm{g} \cdot \cos \alpha \cdot \bar{\mu} \cdot s$

From Eq. (13) follows:

$\bar{v}=\sqrt{2 \cdot \mathrm{g} \cdot(\sin \alpha-\bar{\mu} \cdot \cos \alpha)} \cdot s^{\frac{1}{2}}$ 
i.e.:

$$
\frac{\mathrm{d} s}{\mathrm{~d} t}=\sqrt{2 \cdot \mathrm{g} \cdot(\sin \alpha-\bar{\mu} \cdot \cos \alpha)} \cdot s^{\frac{1}{2}}
$$

which gives:

$$
s^{-\frac{1}{2}} \cdot \mathrm{d} s=\sqrt{2 \cdot \mathrm{g} \cdot(\sin \alpha-\bar{\mu} \cdot \cos \alpha)} \cdot \mathrm{d} t
$$

i.e.:

$\int s^{-\frac{1}{2}} \cdot \mathrm{d} s=\int \sqrt{2 \cdot \mathrm{g} \cdot(\sin \alpha-\bar{\mu} \cdot \cos \alpha)} \cdot \mathrm{d} t$

where from follows:

$$
2 \cdot s^{\frac{1}{2}}=\sqrt{2 \cdot \mathrm{g} \cdot(\sin \alpha-\bar{\mu} \cdot \cos \alpha)} \cdot t_{\mu}+\mathrm{C}
$$

i.e.:

$s=\frac{1}{2} \cdot g \cdot(\sin \alpha-\bar{\mu} \cdot \cos \alpha) \cdot t_{\mu}^{2}$

$\bar{v}=\mathrm{g} \cdot(\sin \alpha-\bar{\mu} \cdot \cos \alpha) \cdot t_{\mu}$

Here the constant $\mathrm{C}=0$ follows from the initial conditions $t=0$ and $s=0$.

To travel the same distance, the body sliding along the inclined plane with friction needs more time $\left(t_{\mu}\right)$ than the body sliding without friction $\left(t_{0}\right)$. If the distances travelled are the same in both cases, then Eq. (7) and Eq. (19) can be equalled, which leads to:

$t_{0}^{2} \cdot \sin \alpha=(\sin \alpha-\bar{\mu} \cdot \cos \alpha) \cdot t_{\mu}^{2}$

Solving Eq. (21) for the mean kinetic friction coefficient $\bar{\mu}$, yields:

$\bar{\mu}=\left[1-\left(\frac{t_{0}}{t_{\mu}}\right)^{2}\right] \cdot \operatorname{tg} \alpha$

Based on Eq. (22) one concludes that the mean kinetic friction coefficient $\bar{\mu}$ can be determined if the angle of inclined plane $\alpha$ is known, as well as the times $t_{0}$ and $t_{\mu}$ which are required for the travel along distance $s$ without ( $\left.t_{0}\right)$ and with friction $\left(t_{\mu}\right)$. The time $t_{0}$ can be calculated from Eq. (8), while the time $t_{\mu}$ can be determined experimentally.

Presented within previous theoretical discussion is a model for determination of mean friction coefficient along a particular travel distance. From a theoretical standpoint, the calculation boils down to knowing the distance law $s(t)$, which can be determined from experimental measurements.

\section{EXPERIMENTAL INVESTIGATIONS}

To calculate the time $t_{\mu}$ required travelling the distance $s$ in real conditions (with friction), the following measurement scheme was considered (Fig. 3).

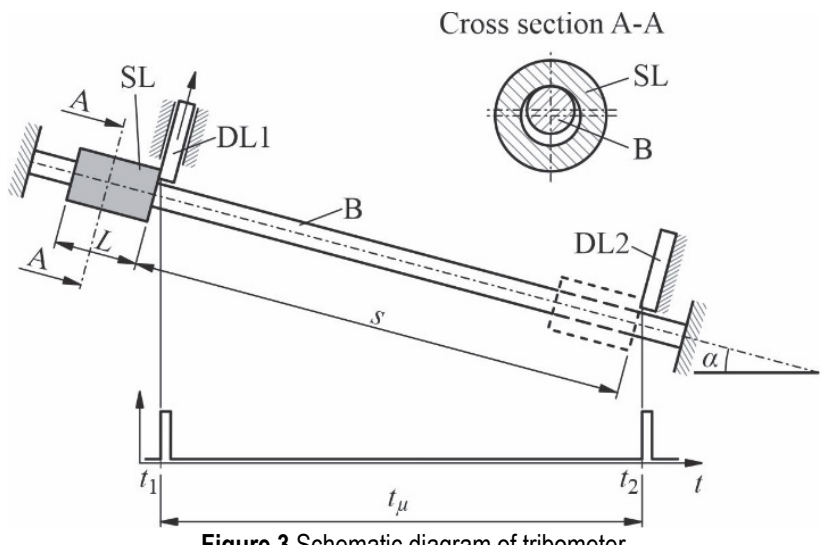

Slider SL, of mass $m$, shaped like a hollow cylinder, is slid down a beam B with a circular cross-section. In this way, the slider SL and the beam B form a contact pair with a theoretical contact interface along a line whose length is $L$. The slope of the inclined plane is defined by the beam at an angle $\alpha$. In its initial position, sliding delimiter DL1 prevents the slider SL from sliding down the beam B. Once the delimiter DL1 is moved to its upper position (Fig. 3), the slider SL is no more constrained and can begin to slide down the plane. The moment which represents the beginning of unconstrained sliding due to DL1 movement is represented with $t_{1}$ in Fig. 3 .

The distance travelled by the slider SL is determined by the position of the fixed delimiter DL2. The moment when the slider SL touches the fixed delimiter, is marked with $t_{2}$ in Fig. 3. The time required for the slider SL to cross the distances equals $t_{\mu}=t_{2}-t_{1}$.

Schematic depiction given in Fig. 3 was used to design the tribometer which was subsequently used for experimental determination of the mean kinetic friction coefficient by measuring the time of travel along path $s$. Completed tribometer is shown in Fig. 4.

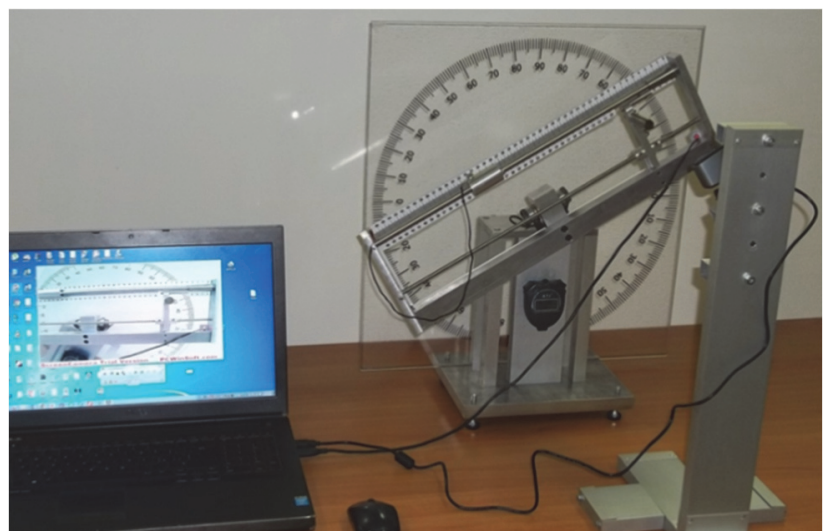

Figure 4 Tribometer for the measurement of mean kinetic friction coefficient 
The beam B is of a circular cross-section with $10 \mathrm{~mm}$ diameter. The slider SL is a hollow cylinder with $10.2 \mathrm{~mm}$ inner, and $15 \mathrm{~mm}$ outer diameter, it is $40 \mathrm{~mm}$ long and has a mass of $29,6 \mathrm{~g}$. The beam B and slider SL are made of austenitic stainless steel AISI Type 316, with the following chemical composition: $16 \div 18 \% \mathrm{Cr}, 10 \div 14 \% \mathrm{Ni}, 2 \div 3 \%$ Mo, $<2 \% \mathrm{Mn},<1 \% \mathrm{Si},<0,1 \% \mathrm{~N},<0,08 \% \mathrm{C},<0,045 \%$ $\mathrm{P},<0,03 \% \mathrm{~S}$, balance Fe. Mechanical and physical properties are as follows: density $7800 \mathrm{~kg} / \mathrm{m}^{3}$, Poisson coefficient 0,30 , elastic modulus $193 \mathrm{GPa}$, tensile strength $515 \mathrm{MPa}$, elongation 40\%, and hardness $90 \mathrm{HRB}$. Arithmetical mean roughness values for the beam and slider are $R a=0,6 \div 0,7 \mu \mathrm{m}$, and $R a=0,7 \div 0,9 \mu \mathrm{m}$, respectively.

The tilting of the inclined plane is regulated using a worm gear train. Positioning error of the inclined plane equals 1'. Delimiters DL1 and DL2 are also used to trigger the stopwatch which registers times $t_{1}$ and $t_{2}$, timing the interval $t_{\mu}$ with $0,01 \mathrm{~s}$ accuracy. The distance travelled by the slider SL equals $s=395 \mathrm{~mm}$.

Experimental determination of the mean kinetic friction coefficient $\bar{\mu}$ was performed for the plane angles $\alpha$ of $16^{\circ}, 19^{\circ}$ and $29^{\circ}$. At each of the plane angles, a total of 30 experiments $(n=30)$ were performed with the resulting time of travel $t_{\mu}$ required for the distance $s$. Based on experimental results, mean kinetic friction coefficients $\bar{\mu}$ and mean sliding velocities $\bar{v}$ were calculated. Normal load of contact interface was calculated based on $F_{\mathrm{n}}=m \cdot \mathrm{g} \cdot \cos \alpha$.

Tab. 1 shows the experimental results, while in Tab. 2 the descriptive statistics of the obtained results is given. The diagram showing the change of mean kinetic friction coefficient through experiments is presented in Fig. 5. The mean kinetic friction coefficient increases with increasing mean sliding velocity, i.e. with decreasing sliding time. The highest average value of mean kinetic friction coefficient ( $\overline{\bar{\mu}}=0,3451$ ) was obtained for the plane angle of $\alpha=29^{\circ}$ and average value of mean sliding velocity of $\overline{\bar{v}}=1,1894 \mathrm{~m} / \mathrm{s}$. The lowest average value of mean kinetic friction coefficient ( $\overline{\bar{\mu}}=0,2072$ ) was obtained for the plane angle of $\alpha=16^{\circ}$ and the average value of mean sliding velocity of $\overline{\bar{v}}=0,7681 \mathrm{~m} / \mathrm{s}$.

Furthermore, with increasing mean sliding velocity and mean kinetic friction coefficient, the errors and deviations of the measured results increase, which affects the increase of the range and confidence levels of the measured results. The deviation of friction coefficients grows with the sliding velocity. The highest deviation of friction coefficient is observed at the plane angle of $\alpha=29^{\circ}$ and the average value of the mean sliding velocity of $1,1894 \mathrm{~m} / \mathrm{s}$.

Table 1 Experimental results

\begin{tabular}{|c|c|c|c|c|c|c|c|c|c|}
\hline \multirow{4}{*}{$n$} & \multirow{3}{*}{\multicolumn{3}{|c|}{$\begin{array}{c}\alpha=16^{\circ}, t_{0}=0,536 \mathrm{~s} \\
F_{\mathrm{n}}=0,279 \mathrm{~N}\end{array}$}} & \multirow{3}{*}{\multicolumn{3}{|c|}{$\begin{array}{c}\alpha=19^{\circ}, t_{0}=0,502 \mathrm{~s} \\
F_{\mathrm{n}}=0,274 \mathrm{~N}\end{array}$}} & \multirow{3}{*}{\multicolumn{3}{|c|}{$\begin{array}{c}\alpha=29^{\circ}, t_{0}=0,408 \mathrm{~s} \\
F_{\mathrm{n}}=0,254 \mathrm{~N}\end{array}$}} \\
\hline & & & & & & & & & \\
\hline & & & & & & & & & \\
\hline & $t_{\mu} / \mathrm{s}$ & $\bar{\mu} /-$ & $\bar{v} / \mathrm{m} / \mathrm{s}$ & $t_{\mu} / \mathrm{s}$ & $\bar{\mu} /-$ & $\bar{v} / \mathrm{m} / \mathrm{s}$ & $t_{\mu} / \mathrm{s}$ & $\bar{\mu} /-$ & $\bar{v} / \mathrm{m} / \mathrm{s}$ \\
\hline 1 & 1,02 & 0,2062 & 0,7747 & 1,11 & 0,2752 & 0,7117 & 0,67 & 0,3492 & 1,1791 \\
\hline 2 & 1,02 & 0,2062 & 0,7747 & 1,27 & 0,2915 & 0,6223 & 0,64 & 0,3295 & 1,2345 \\
\hline 3 & 1,11 & 0,2188 & 0,7112 & 0,87 & 0,2318 & 0,9081 & 0,71 & 0,3717 & 1,1124 \\
\hline 4 & 1,15 & 0,2234 & 0,6869 & 0,86 & 0,2292 & 0,9184 & 0,67 & 0,3492 & 1,1791 \\
\hline 5 & 1,11 & 0,2188 & 0,7112 & 0,89 & 0,2368 & 0,8877 & 0,64 & 0,3295 & 1,2345 \\
\hline 6 & 1,05 & 0,2108 & 0,7520 & 0,87 & 0,2318 & 0,9081 & 0,61 & 0,3069 & 1,2949 \\
\hline 7 & 0,93 & 0,1899 & 0,8493 & 0,93 & 0,2459 & 0,8491 & 0,68 & 0,3552 & 1,1617 \\
\hline 8 & 1,02 & 0,2062 & 0,7747 & 1,09 & 0,2726 & 0,7252 & 0,71 & 0,3717 & 1,1124 \\
\hline 9 & 1,02 & 0,2062 & 0,7747 & 0,96 & 0,2519 & 0,8230 & 0,71 & 0,3717 & 1,1124 \\
\hline 10 & 1,02 & 0,2062 & 0,7747 & 0,86 & 0,2292 & 0,9184 & 0,68 & 0,3552 & 1,1617 \\
\hline 11 & 1,02 & 0,2062 & 0,7747 & 0,96 & 0,2519 & 0,8230 & 0,68 & 0,3552 & 1,1617 \\
\hline 12 & 0,96 & 0,1958 & 0,8233 & 0,96 & 0,2519 & 0,8230 & 0,71 & 0,3717 & 1,1124 \\
\hline 13 & 1,08 & 0,2149 & 0,7317 & 1,02 & 0,2625 & 0,7742 & 0,62 & 0,3148 & 1,2741 \\
\hline 14 & 0,93 & 0,1899 & 0,8493 & 0,96 & 0,2519 & 0,8230 & 0,64 & 0,3295 & 1,2345 \\
\hline 15 & 0,92 & 0,1878 & 0,8584 & 0,99 & 0,2574 & 0,7982 & 0,67 & 0,3492 & 1,1791 \\
\hline 16 & 1,02 & 0,2062 & 0,7747 & 0,96 & 0,2519 & 0,8230 & 0,64 & 0,3295 & 1,2345 \\
\hline 17 & 1,11 & 0,2188 & 0,7112 & 0,96 & 0,2519 & 0,8230 & 0,62 & 0,3148 & 1,2741 \\
\hline 18 & 1,14 & 0,2223 & 0,6928 & 1,05 & 0,2671 & 0,7521 & 0,71 & 0,3717 & 1,1124 \\
\hline 19 & 1,02 & 0,2062 & 0,7747 & 0,81 & 0,2145 & 0,9754 & 0,71 & 0,3717 & 1,1124 \\
\hline 20 & 1,02 & 0,2062 & 0,7747 & 0,87 & 0,2318 & 0,9081 & 0,65 & 0,3364 & 1,2153 \\
\hline 21 & 1,05 & 0,2108 & 0,7520 & 0,90 & 0,2392 & 0,8776 & 0,68 & 0,3552 & 1,1617 \\
\hline 22 & 1,11 & 0,2188 & 0,7112 & 0,90 & 0,2392 & 0,8776 & 0,64 & 0,3295 & 1,2345 \\
\hline 23 & 1,08 & 0,2149 & 0,7317 & 0,93 & 0,2459 & 0,8491 & 0,67 & 0,3492 & 1,1791 \\
\hline 24 & 1,02 & 0,2062 & 0,7747 & 0,89 & 0,2368 & 0,8877 & 0,68 & 0,3552 & 1,1617 \\
\hline 25 & 1,14 & 0,2223 & 0,6928 & 0,89 & 0,2368 & 0,8877 & 0,71 & 0,3717 & 1,1124 \\
\hline 26 & 0,93 & 0,1899 & 0,8493 & 0,83 & 0,2207 & 0,9518 & 0,64 & 0,3295 & 1,2345 \\
\hline 27 & 1,05 & 0,2108 & 0,7520 & 0,89 & 0,2368 & 0,8877 & 0,61 & 0,3069 & 1,2949 \\
\hline 28 & 1,02 & 0,2062 & 0,7747 & 0,86 & 0,2292 & 0,9184 & 0,65 & 0,3364 & 1,2153 \\
\hline 29 & 0,96 & 0,1958 & 0,8233 & 0,90 & 0,2392 & 0,8776 & 0,65 & 0,3364 & 1,2153 \\
\hline 30 & 0,95 & 0,1939 & 0,8318 & 0,93 & 0,2459 & 0,8491 & 0,67 & 0,3492 & 1,1791 \\
\hline
\end{tabular}

On the other hand, the lowest deviation is characteristic of plane angle of $\alpha=16^{\circ}$ and the average value of mean sliding velocity which amounts to 0,7681 $\mathrm{m} / \mathrm{s}$. The obtained results for skewness indicate that all experimental results are fairly or moderately skewed (negatively and/or positively). The obtained results of kurtosis indicate that most of the experimental results have low kurtosis (distribution is shorter), except for the sliding time with friction for $\alpha=19^{\circ}$ whose value of kurtosis indicates the existence of outliers. 


\begin{tabular}{|c|c|c|c|c|c|c|c|c|c|}
\hline \multirow{3}{*}{ Parameter } & \multirow{2}{*}{\multicolumn{3}{|c|}{$\begin{array}{c}\alpha=16^{\circ}, t_{0}=0,536 \mathrm{~s} \\
F_{\mathrm{n}}=0,279 \mathrm{~N}\end{array}$}} & \multirow{2}{*}{\multicolumn{3}{|c|}{$\begin{array}{c}\alpha=19^{\circ}, t_{0}=0,502 \mathrm{~s} \\
F=0274 \mathrm{~N}\end{array}$}} & \multicolumn{3}{|c|}{$\alpha=29^{\circ}, t_{0}=0,408 \mathrm{~s}$} \\
\hline & & & & & & & & $F_{\mathrm{n}}=0,254 \mathrm{~N}$ & \\
\hline & $t_{\mu} / \mathrm{s}$ & $\bar{\mu} /-$ & $\bar{v} / \mathrm{m} / \mathrm{s}$ & $t_{\mu} / \mathrm{s}$ & $\bar{\mu} /-$ & $\bar{v} / \mathrm{m} / \mathrm{s}$ & $t_{\mu} / \mathrm{s}$ & $\bar{\mu} /-$ & $\bar{v} / \mathrm{m} / \mathrm{s}$ \\
\hline Mean & 1,0327 & 0,2072 & 0,7681 & 0,9390 & 0,2453 & 0,8486 & 0,6657 & 0,3451 & 1,1894 \\
\hline Standard Error & 0,0122 & 0,0019 & 0,0092 & 0,0173 & 0,0031 & 0,0139 & 0,0059 & 0,0037 & 0,0105 \\
\hline Standard Deviation & 0,0668 & 0,0104 & 0,0501 & 0,0950 & 0,0168 & 0,0759 & 0,0321 & 0,0203 & 0,0577 \\
\hline Kurtosis & $-0,7763$ & $-0,6930$ & $-0,7493$ & 4,0686 & 0,7984 & 1,5533 & $-1,0309$ & $-0,8854$ & $-0,9485$ \\
\hline Skewness & 0,0167 & $-0,3257$ & 0,2065 & 1,7345 & 0,7569 & $-1,0554$ & $-0,0261$ & $-0,2428$ & 0,1660 \\
\hline Range & 0,23 & 0,0356 & 0,1715 & 0,46 & 0,0770 & 0,3531 & 0,1 & 0,0648 & 0,1825 \\
\hline Minimum & 0,92 & 0,1878 & 0,6869 & 0,81 & 0,2145 & 0,6223 & 0,61 & 0,3069 & 1,1124 \\
\hline Maximum & 1,15 & 0,2234 & 0,8584 & 1,27 & 0,2915 & 0,9754 & 0,71 & 0,3717 & 1,2949 \\
\hline $\begin{array}{l}\text { Confidence Level } \\
(95 \%)\end{array}$ & 0,0250 & 0,0039 & 0,0187 & 0,0355 & 0,0063 & 0,0283 & 0,0120 & 0,0076 & 0,0216 \\
\hline $\begin{array}{l}\text { Confidence } \\
\text { Interval }(95 \%)\end{array}$ & $\begin{array}{c}(1,0077 \div 1,0 \\
577)\end{array}$ & $\begin{array}{c}(0,2033 \div 0,2 \\
111)\end{array}$ & $\begin{array}{c}(0,7494 \div 0,7 \\
868)\end{array}$ & $\begin{array}{c}(0,9035 \div 0,9 \\
745)\end{array}$ & $\begin{array}{c}(0,2390 \div 0,2 \\
516)\end{array}$ & $\begin{array}{c}(0,8203 \div 0,8 \\
769)\end{array}$ & $\begin{array}{c}(06537 \div 0,6 \\
777)\end{array}$ & $\begin{array}{c}(0,3375 \div 0,3 \\
527)\end{array}$ & $\begin{array}{c}(1,1678 \div 1,21 \\
10)\end{array}$ \\
\hline
\end{tabular}
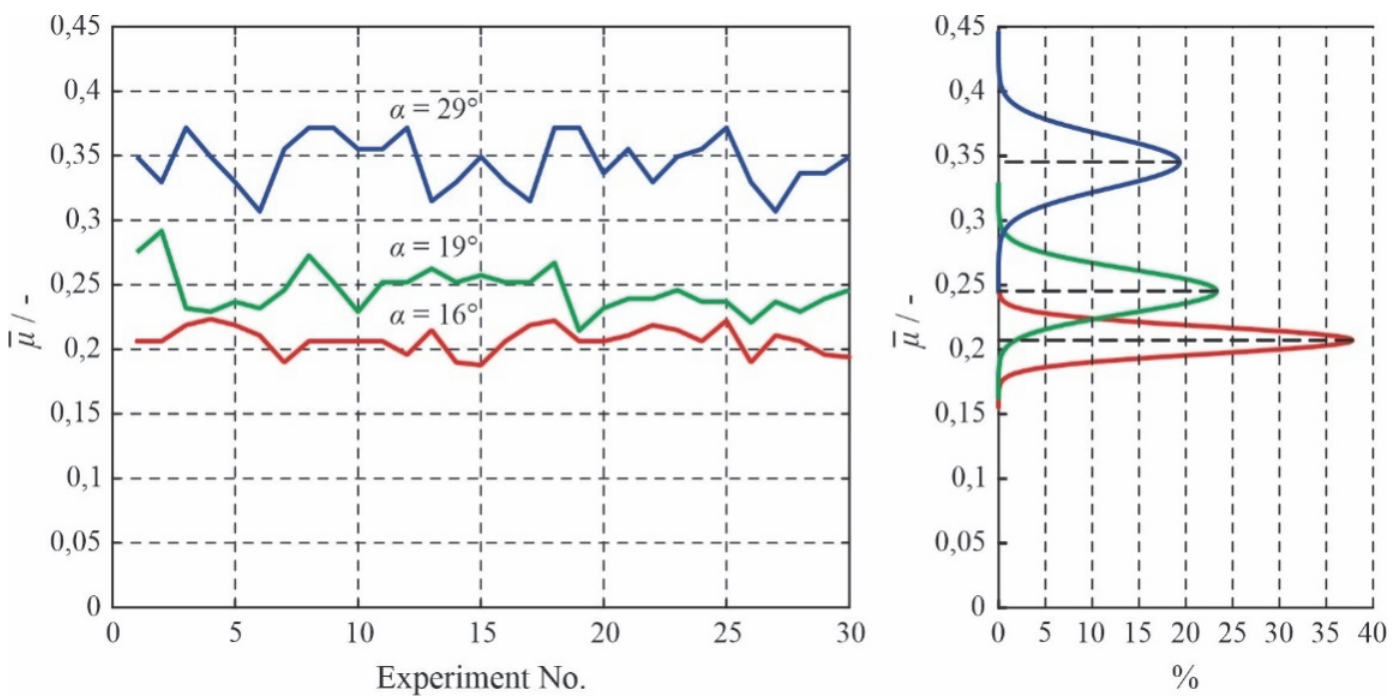

Figure 5 Change of mean kinetic friction coefficient

On the other hand, the lowest deviation is characteristic of plane angle of $\alpha=16^{\circ}$ and the average value of mean sliding velocity which amounts to 0,7681 $\mathrm{m} / \mathrm{s}$. The obtained results for skewness indicate that all experimental results are fairly or moderately skewed (negatively and/or positively). The obtained results of kurtosis indicate that most of the experimental results have low kurtosis (distribution is shorter), except for the sliding time with friction for $\alpha=19^{\circ}$ whose value of kurtosis indicates the existence of outliers.

Using known values for normal load $F_{\mathrm{n}}$, and knowing the contact type (cylinder in cylinder), contact pressure can be calculated based on well-known expressions from the theory of elasticity:

$p=\sqrt{\frac{q}{v \cdot\left(k_{1}+k_{2}\right)}}$

where:

$$
\begin{aligned}
& v=\frac{2 \cdot R_{\mathrm{g}} \cdot R_{\mathrm{c}}}{R_{\mathrm{g}}-R_{\mathrm{c}}} \\
& k_{1}=\frac{1-\mu_{1}^{2}}{E_{1}}
\end{aligned}
$$

$$
k_{2}=\frac{1-\mu_{2}^{2}}{E_{2}}
$$

Here, $p$ is the contact pressure, $q$ is the load per unit length of cylinder, $R_{\mathrm{c}}$ is the radius of the beam, $R_{\mathrm{g}}$ is the slider groove radius, $\mu_{1}$ is the Poisson ratio for beam material, $\mu_{2}$ is the Poisson ratio for slider material, $E_{1}$ is the elasticity module for beam material, and $E_{2}$ is the elasticity module for sliding material.

Considering that the beam and slider are made of the same material, there follows that $\mu_{1}=\mu_{2}$ and $E_{1}=E_{2}$. Based on the calculations according to Eq. (23), the theoretical contact pressure ranged from 1,15 to 1,21 MPa. As shown, experimental investigation was performed at low contact pressures which yield relatively higher values of friction coefficient.

\section{DISCUSSION}

The authors of this paper maintain that the discussion of the presented theoretical model and the corresponding results should be directed towards the energy consumed in the friction process. With this in mind, we consider the diagram of friction force versus distance $s$ (Fig. 2). Sliding along the inclined plane begins from immobility, and after distance $s$ reaches its maximum velocity. The initial moment of displacement is characterized by maximum 
friction force, which gradually drops as the sliding velocity increases.

As previously shown within the theoretical presentation and graphically illustrated (Fig. 2), regardless of variations in the friction force values during sliding, there follows:

$$
A_{F_{\mu}}=\int_{0}^{s \overline{\mathrm{OA}}} F_{\mu}(s) \cdot \mathrm{d} s=\bar{F}_{\mu} \cdot s \overline{\mathrm{OA}}=\bar{\mu} \cdot m \cdot \mathrm{g} \cdot \cos \alpha \cdot s \overline{\mathrm{OA}}
$$

Based on this equation, the total work of the friction force $A_{F \mu}$ i.e., energy $E$, consumed due to sliding friction, can be determined using mean kinetic friction coefficient regardless of the variation of friction force with the distance.

$$
E=\bar{\mu} \cdot m \cdot \mathrm{g} \cdot \cos \alpha \cdot s \overline{\mathrm{OA}}
$$

where:

$$
\bar{\mu}=\frac{E}{m \cdot \mathrm{g} \cdot \cos \alpha \cdot s \overline{\mathrm{OA}}}
$$

i.e.:

$$
\bar{\mu}=k \cdot E
$$

where:

$$
k=\frac{1}{m \cdot \mathrm{g} \cdot \cos \alpha \cdot s \overline{\mathrm{OA}}}
$$

is constant for the given conditions of experiment.

From the previous discussion there follows that the mean friction coefficient $\bar{\mu}$ practically represents the energy consumed due to friction, for the given experimental conditions.

Experimental results given in Tab. 1, and Eq. (28) yield values of energy consumed due to friction: $E_{\alpha=16^{\circ}}=$ $0,022844 \mathrm{~J}, E_{\alpha=19^{\circ}}=0,026602 \mathrm{~J}$, and $E_{\alpha=29^{\circ}}=0,034618 \mathrm{~J}$.

Within the theoretical model (Fig. 1), air resistance force $F_{\mathrm{w}}$ was disregarded. Following is the justification for this simplification.

A body with the frontal surface area $A$ which travels at velocity $v$ through the air of density $\rho_{\mathrm{w}}$ is attacked by the following air resistance force:

$$
F_{\mathrm{w}}=\frac{1}{2} \cdot C_{\mathrm{D}} \cdot \rho_{\mathrm{w}} \cdot A \cdot v^{2}
$$

where $C_{\mathrm{D}}$ is the drag coefficient which is determined experimentally, most often in air tunnels. It depends on body geometry, size, orientation in the air stream, and surface smoothness. In order to assess the influence of air resistance, let us introduce coefficient $\xi$ which represents the ratio between the air resistance force and friction force, i.e.:

$$
\xi=\frac{F_{\mathrm{w}}}{F_{\mu}}
$$
follows:

Substituting Eq. (2) and Eq. (32) into Eq. (33), there

$$
\xi=\frac{C_{\mathrm{D}} \cdot \rho_{\mathrm{w}} \cdot A \cdot v^{2}}{2 \cdot \mu \cdot m \cdot \mathrm{g} \cdot \cos \alpha}
$$

Body mass $m$ can be determined as follows:

$$
m=\rho_{\mathrm{m}} \cdot V_{\mathrm{m}}
$$

where $\rho_{\mathrm{m}}$ and $V_{\mathrm{m}}$ are density and volume, respectively.

Volume of the hollow cylinder, used in this experiment, is $V_{\mathrm{m}}=A \cdot L$, where $L$ is body length, while $A$ denotes surface area. Considering movement in air, $A$ denotes the frontal surface acted upon by the air resistance force - as shown on the model of slider SL in Fig. 3 (crosssection A-A). Eq. (35) can be expressed as:

$$
m=\rho_{\mathrm{m}} \cdot A \cdot L
$$

Introducing Eq. (36) into Eq. (34), yields:

$$
\xi=\frac{C_{\mathrm{D}} \cdot \rho_{\mathrm{w}} \cdot v^{2}}{2 \cdot \mu \cdot \rho_{\mathrm{m}} \cdot L \cdot \mathrm{g} \cdot \cos \alpha}
$$

Let us consider a case of a stainless steel body sliding down an inclined plane, as was the case in this investigation. In that case, $\rho_{\mathrm{m}}=7,8 \cdot 10^{3} \mathrm{~kg} / \mathrm{m}^{3}$ and $\rho_{\mathrm{w}}=1$ $\mathrm{kg} / \mathrm{m}^{3}$. For the geometry of the slider body under consideration (Fig. 3), $L=0,04 \mathrm{~m}$. In general case, the drag coefficient can be adopted as $C_{\mathrm{D}} \approx 0,8$. Now, Eq. (37) can be written as:

$$
\xi \approx 1,3 \cdot 10^{-4} \cdot \frac{v^{2}}{\mu \cdot \cos \alpha}
$$

The diagram showing the change of friction coefficient $\xi$ given by Eq. (38), as the function of sliding velocity $v$ in the case of $\mu \cdot \cos \alpha$ is shown in Fig. 6 .

Based on the results of experimental investigation from Tab. 1, and the Eq. (38), one can calculate coefficient $\xi$ which equals $\xi_{\alpha=16^{0}}=9,55 \cdot 10^{-5}, \xi_{\alpha=19^{\circ}}=9,92 \cdot 10^{-5}$, and $\xi_{\alpha=29^{\circ}}=1,52 \cdot 10^{-4}$.

Even in the worst-case scenario, the air resistance force $F_{\mathrm{w}}$ is approximately 6500 times lower than the friction force $F_{\mu}$. In other words, given the conditions of the experiment reported in this study, air resistance force can be neglected. 


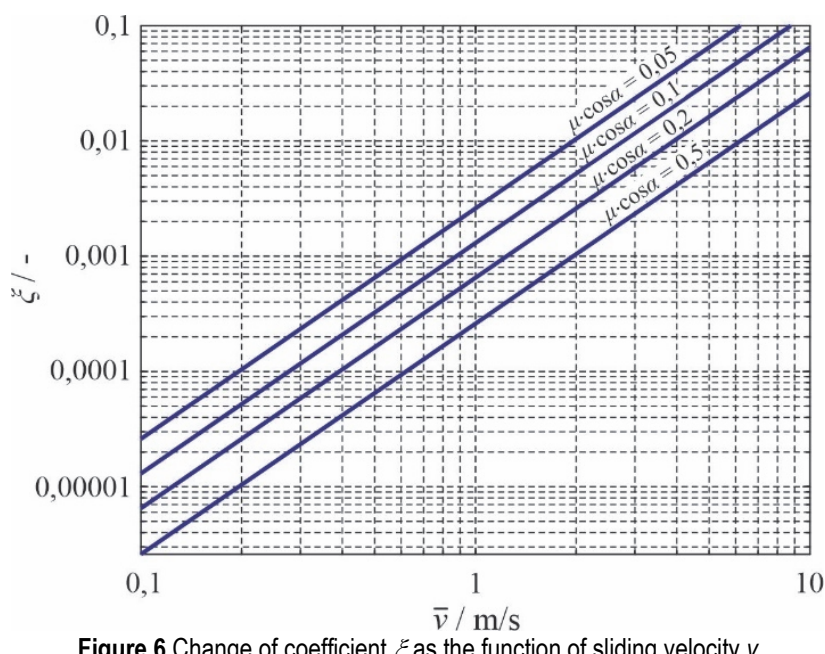

Figure 6 Change of coefficient $\xi$ as the function of sliding velocity $v$

\section{CONCLUSION}

Previous design solutions of tribometers allow determination of friction force and normal loads under various conditions of contact interface formation. Kinetic friction coefficient is determined from the measured values of friction force and normal load.

The method proposed in this study which allows determination of kinetic friction coefficient and energy consumed due to friction, is based on different premises. The discussed model draws on the equation which describes body sliding down an inclined plane. It requires only time measurement to determine kinetic friction coefficient and energy consumed due to friction. Compared to other methods, the proposed model has a number of advantages considering the basic theoretical method, model simplicity and reliability, as well as the potential for industrial application.

The results of measurement presented in the experimental section of this study are compatible with the results obtained by conventional measurement methods. Compared to other methods, the proposed method for determination of energy consumed due to friction and the friction coefficient is less technically demanding due to simplicity of employed measuring system. The method can be efficiently used in tribological experiments at high temperatures in vacuum, friction in controlled gas environments, and other frictional conditions.

It is of special importance that the proposed method allows quantification of friction parameters of real industrial products (sliding guides, etc.) owing to the simple requirement to measure travel time. Existing methods and realized tribometer design solutions are based on model tests which always lead to deviations when compared to results obtained on real industrial products.

Future research will be focused on upgrading the measurement instrumentation in terms of increasing the accuracy and precision of measuring the sliding time and distance. This will increase the accuracy and precision of the measurement of kinetic friction coefficient, obtaining smaller errors and deviations, thus reducing the measurement uncertainty.

The plan is to upgrade the tribometer with a larger number of sensors to measure the time on certain sections of the travel distance. If the distance law is known, i.e. the dependence of the distance travelled on time, it is possible to obtain the current value of the kinetic friction coefficient. When time tends to infinity, the mean kinetic friction coefficient is transformed into the current kinetic friction coefficient. Furthermore, future research will be focused on defining kinetic friction coefficient for contact pairs made of different materials, with different qualities of contact surfaces, under different microclimatic conditions (temperature, pressure, and humidity), etc.

\section{REFERENCES}

[1] Hutchings, M. I. (2016). Leonardo da Vinci's studies of friction. Wear, 360-361, 51-66. https://doi.org/10.1016/j.wear.2016.04.019

[2] Deladi, E. L. (2006). Static Friction in Rubber-Metal Contacts with Application to Rubber Pad Forming Processes. PhD thesis. Twente: University of Twente.

[3] Blau, J. P. (2001). The significance and use of the friction coefficient. Tribology International, 34(9), 585-591. https://doi.org/10.1016/S0301-679X(01)00050-0

[4] Ivkovic, B., Djurdjanovic, M., \& Stamenkovic, D. (2000). The Influence of the Contact Surface Roughness on the Static Friction Coefficient. Tribology in Industry, 22(3-4), 41-44.

[5] Mullerm, U. \& Hauertm, R. (2003). Investigations of the coefficient of static friction diamond-like carbon films. Surface and Coatings Technology, 174-175, 421-426. https://doi.org/10.1016/S0257-8972(03)00421-3

[6] Polyakov, B., Vlassov, S., Dorogin, M. L., Kulis, P., Kink, I., \& Lohmus, R. (2012). The effect of substrate roughness on the static friction of $\mathrm{CuO}$ nanowires. Surface Science, 606(17-18), 1393-1399. https://doi.org/10.1016/j.susc.2012.04.029

[7] Bhushan, B., Sundararajan, S., Scott, W. W. \& Chilamakuri, S. (1997). Stiction analysis of magnetic tapes. IEEE Transactions on Magnetics, 33(5), 3211-3213. https://doi.org/10.1109/20.617894

[8] Kogut, L. \& Etsion, I. (2004). A Static Friction Model for Elastic-Plastic Contacting Rough Surfaces. Journal of Tribology, 126, 34-40. https://doi.org/10.1115/1.1609488

[9] Cohen, D., Kligerman, Y., \& Etsion, I. (2008). A Model for Contact and Static Friction of Nominally Flat Rough Surfaces under Full Stick Contact Condition. Journal of Tribology, 130(3). https://doi.org/10.1115/1.2908925

[10] Ibrahim Dickey, D. R., Jackson, L. R., \& Flowers, T. G. (2011). Measurements of the Static Friction Coefficient between Tin Surfaces and Comparison to a Theoretical Model. Journal of Tribology, 133(3), 031408. https://doi.org/10.1115/1.4004338

[11] Fujii, Y. (2008). Method for measuring transient friction coefficients for rubber wiper blades on glass surface. Tribology International, 41(1), 17-23. https://doi.org/10.1016/j.triboint.2007.04.003

[12] Hwang, H. D. \& Zum Gahra, H. K. (2003). Transition from static to kinetic friction of unlubricated or oil lubricated steel/steel, steel/ceramic and ceramic/ceramic pairs. Wear, 255(1-6), 365-375. https://doi.org/10.1016/S0043-1648(03)00063-2

[13] Al-Bender, F. \& De Moerlooze, K. (2010). On the relationship between normal load and friction force in presliding frictional contacts. Part 1: Theoretical analysis. Wear, 269(3-4), 174-182. https://doi.org/10.1016/j.wear.2010.02.010

[14] Benabdallah, S. H. (2007). Static friction coefficient of some plastics against steel and aluminum under different contact conditions. Tribology International, 40, 64-73. https://doi.org/10.1016/j.triboint.2006.02.031

[15] Ando, Y., Tamura, Y., Takahashi, H., \& Hiratsuka, K. (2012). Experimental Studies on Revealing a Dominant 
Factor in Friction Coefficient between Different Metals under Low Load Conditions. Tribology Letters, 47, 43-49. https://doi.org/10.1007/s11249-012-9960-5

[16] Podgursky, V., Adoberg, E., Surzenkov, A., Kimmari, E., Viljus, M., Mikli, V., Hartelt, M., Wasche, R., Sima, M., \& Kulu, K. (2011). Dependence of the friction coefficient on roughness parameters during early stage fretting of (Al, Ti) $\mathrm{N}$ coated surfaces. Wear, 271(5-6), 853-858. https://doi.org/10.1016/j.wear.2011.03.006

[17] Tayebi, N. \& Polycarpou, A. A. (2004). Modeling the effect of skewness and kurtosis on the static friction coefficient of rough surfaces. Tribology International, 37, 491-505. https://doi.org/10.1016/j.triboint.2003.11.010

[18] Sedlacek, M., Podgornik, B., \& Vizintin, J. (2009). Influence of surface preparation on roughness parameters, friction and wear. Wear, 266(3-4), 482-487. https://doi.org/10.1016/j.wear.2008.04.017

[19] Zhou, Y., Zhu, H., Zuo, X., Li, Y., \& Chen, N. (2015).The nonlinear nature of friction coefficient in lubricated sliding friction. Tribology International, 88, 8-16. https://doi.org/10.1016/j.triboint.2015.02.027

[20] Chaikittiratana, A., Koetniyom, S., \& Lakkam, S. (2012). Static/kinetic Friction Behaviour of a Clutch Facing Material: Effects of Temperature and Pressure.International Journal of Mechanical, Aerospace, Industrial, Mechatronic and Manufacturing Engineering, 6, 1048-1051.

[21] Cho, D. H., Bhushan, B., \& Dyess, J. (2016). Mechanisms of static and kinetic friction of polypropylene, polyethylene terephthalate, and high-density polyethylene pairs during sliding. Tribology International, 94, 165-175. https://doi.org/10.1016/j.triboint.2015.08.027

[22] Cho, D. H., \& Bhushan, B. (2016). Friction and wear of various polymer pairs used for label and wiper in labeling machine. Tribology International, 98, 10-19. https://doi.org/10.1016/j.triboint.2016.02.019

[23] Jeremic, B., Vukelic, D., Todorovic, M. P., Macuzic, I., Pantic, M., Dzunic, D., \& Tadic, B. (2013). Static Friction at High Contact Temperatures and Low Contact Pressure. Journal of Friction and Wear, 34, 114-119. https://doi.org/10.3103/S1068366613020037

[24] Kumar, H., Ramakrishnan, V., Albert, S. K., Meikandamurthy, C., Tata, B. V. R., \& Bhaduri, A. K (2010). High temperature wear and friction behavior of $15 \mathrm{Cr}-15 \mathrm{Ni}-2 \mathrm{Mo}$ titanium-modified austenitic stainless steel in liquid sodium. Wear, 270(1-2), 1-4. https://doi.org/10.1016/j.wear.2010.08.015

[25] Yue, T. \& Wahab, A. M. (2017).Finite element analysis of fretting wear under variable coefficient of friction and different contact regimes. Tribology International, 107, 274-282. https://doi.org/10.1016/j.triboint.2016.11.044

[26] Maegawa, S., Itoigawa, F., \& Nakamura, T. (2015). Effect of normal load on friction coefficient for sliding contact between rough rubber surface and rigid smooth plane. Tribology International, 92, 335-343. https://doi.org/10.1016/j.triboint.2015.07.014

[27] Jankowiak, T., Rusinek, A., List, G., Sutter, G., \& Abed, F. (2016). Numerical analysis for optimizing the determination of dynamic friction coefficient. Tribology International, 95, 86-94. https://doi.org/10.1016/j.triboint.2015.10.039

[28] Maru, M. M. \& Tanaka, K. D. (2006). Influence of loading, contamination and additive on the wear of a metallic pair under rotating and reciprocating lubricated sliding. Journal of the Brazilian Society of Mechanical Sciences and Engineering, 28(3), 278-285. https://doi.org/10.1590/S1678-58782006000300005

[29] Tadic, B., Ivkovic, B., \& Todorovic, P. (2002). Theoretical Basis of Pin and Block Carrier Design at Tribometer Tpd2002. Tribology in Industry, 24(3-4), 53-66.

\section{Contact information:}

Djordje VUKELIC, PhD, Full Professor

(Corresponding author)

University of Novi Sad, Faculty of Technical Sciences,

Trg Dositeja Obradovica 6, 21000 Novi Sad, Serbia

E-mail: vukelic@uns.ac.rs

Petar TODOROVIC, PhD, Full Professor

University of Kragujevac, Faculty of Engineering,

Sestre Janjic 6, 34000 Kragujevac, Serbia

E-mail: petar@kg.ac.rs

Katica SIMUNOVIC, PhD, Full Professor

University of Slavonski Brod, Mechanical Engineering Faculty in Slavonski Brod, Trg Ivane Brlic Mazuranic 2, 35000 Slavonski Brod, Croatia

E-mail: ksimun@sfsb.hr

Jasmina MILJOJKOVIC, MSC

University of Kragujevac, Faculty of Engineering,

Sestre Janjic 6, 34000 Kragujevac, Serbia

E-mail: jasmina.miljojkovic@fink.rs

Goran SIMUNOVIC, PhD, Full Professor

University of Slavonski Brod, Mechanical Engineering Faculty in Slavonski Brod, Trg Ivane Brlic Mazuranic 2, 35000 Slavonski Brod, Croatia

E-mail: gsimun@sfsb.hr

Igor BUDAK, PhD, Full Professor

University of Novi Sad, Faculty of Technical Sciences,

Trg Dositeja Obradovica 6, 21000 Novi Sad, Serbia

E-mail: budaki@uns.ac.rs

Branko TADIC, PhD, Full Professor

University of Kragujevac, Faculty of Engineering,

Sestre Janjic 6, 34000 Kragujevac, Serbia

E-mail: btadic@kg.ac.rs 